and when short silk ligature and the drainage-tube became popular. It has always surprised me that he of all men should have followed so blindly a method which he now so loudly decries.

Passing now to the continent of Europe, we find Delaporte proposing the operation in 1774, and in 1798 Chambon said that he was persuaded that a time would come when this operation would be extended to more numerous cases than he had proposed, and that it would not be found difficult to execute. In 1844 Chareau published a paper containing a collection of sixty-five operations, with a mortality of 35.38 per cent. In $1856^{\circ}-1857$, at a great discussion at the French Academy of Medicine, all the best known names in French medicine and surgery were ranged in the opposition, and this checked the progress of the operation in France for several years. Koeberle of Strasburg, who has been one of the leading Continental operators, began in 1862 . The results in France up to 1867 were deplorable, for with 122 operations there was a mortality of nearly 60 per cent. In Germany, Chrysmar, in 1819, first performed the operation, and this was the first case of it in Europe. From 1819 to 1856 sixty-four operations were performed in Germany with the terrible mortality of nearly 72 per cent. Even as late as 1870 the deaths exceeded the recoveries ; but Lister has changed all that, and now the German operators run us very hard in their successes. It would occupy me too long if $I$ were to attempt to follow, even in the brief fashion I have adopted so far, the rise and progress of ovariotomy in other European countries and in India and the colonies ; it must suffice to say that nowhere did it make so good progress as in our own country, and in most places it was very slow in making any progress at all. Before considering in a little more detail the methods employed during these years of slow progress and occasional collapse, I will briefly refer to the operation for the removal of fibroid tumours of the womb and to the few removals of the spleen, which are really the only abdominal operations outside ovariotomy which were even attempted before the great advance of fifteen years ago, at which period I propose afterwards to commence my remarks on present abdominal surgery.

(To be concluded.)

\section{INFECTIVE SUBPERIOSTEAL ABSCESSES.}

BY HERBERT W. PAGE, F.R.C.S. ENG., SURGEON TO ST. MARY'S HOSPITAL.

WHEN suppuration was common and pus was accounted laudable, it is conceivable that some cases of especial interest in the domain of inflammation may have escaped observation, being, so to say, lost in the crowd of surrounding abscesses ; but now that the presence of suppuration is a cause of reproach in all surgically inflicted wounds, and pus is more often brought into a hospital than formed there from the first, any unusual features of certain suppurations are prone to arrest attention. The doctrine of infection with pyogenic organisms has thrown a new light on the origin of many abscesses which were formerly inexplicable and unexplained, and a cause is now seen of suppuration in the joints, for example, in pyæmia, and of the multiple abscesses sometimes found in the more chronic variety of this septic disease. The violent necrotic inflammation which occasionally attacks the growing epiphysial region of the long bones is, moreover, less obscure than it used to be. Examples of these inflammations are seen from time to time in every hospital, and within the past three years I have had under observation some cases of infective suppuration deserving of brief record. Thus, in the case of an infant repeated abscesses appeared in the subcutaneeus tissues during the several weeks it lived, the entry of infection having been presumably at the wound caused by severance of the umbilical cord; and in the case of a man who had had tracheotomy performed preliminary to removal of his tongue, numerous very large and rapidly formed abscesses presented themselves in various parts of the body during the rest of his life, a period of several months, yet always in the subcutaneous tissues. The "selective affinity" thus exercised by the tissues for the infecting virus is manifested even more strikingly by the epiphysial inflammations. In one instance the head of one tibia was attacked, then that of the other, and presently the lower epiphysial region of the same lones followed suit. Mr. Watson Cheyne has dealt very thoroughly with this subject in his valuable lectures, "Suppuration and Septic Diseases," and has the re shown how the "anatomical arrangement of the part," as he terms it, is an important factor in the production of acute osteo-myelitis, not less important, perhaps, than that of the seat of inoculation, dose of the poison, \&c. Injury, he says, and the presence of cocei do not wholly explain the etiology of this disease, which, as a rule, has certain favourite seats. This was well exemplified in the case which has been mentioned, for the disease had its beginning in the head of the one bone which had been locally weakened by injury, while there had been no injury of the other parts attacked, and there must have been something else to determine their involvement in the same suppurative inflamma. tion. It appears, therefore, that for the development of these suppurations there is something more required than injury and the harmful agency of the virus, which need not necessarily have gained entrance by a wounded surface; there is also the selective affinity of the tissues themselves, as determined by the anatomical arrangement of the part. These things were displayed by the following very remarkable case of subperiosteal suppuration which I desire bere to relate.

A schoolboy, twelve years old, was admitted to St. Mary's Hospital on June 4th with a painful swelling below and on the inner side of the left knee. A fortnight previously he had been kicked on the part while at play, but a week went by before the pain became at all severe or he took to bed. The pain then increased, and kept him awake at night, and the place became tender. He lost his appetite, and on admission looked distinctly though not seriously ill. He was wasted, and had a temperature of $103^{\circ} \mathrm{F}$. He had not had a rigor. There was very decided local inflammation at the part, with slight obscure deepseated fluctuation. The site of this inflammation and his history made me fear that I might possibly have before me a case of epiphysial osteo-myelitis, and I accordingly had the boy taken to the theatre at once, and preparations were made for trephining the bone. A free incision through the periosteum let out a few drops of pus, but careful exploration led me to the conclusion that the inflammation was entirely on the surface of the bone, and was unconnected with mischief in the centre of it. His general condition seemed rather to favour this conclusion, for he was hardly ill enough and the local state was hardly bad enough for him to be the subject of an acute bone inflammation of a fortnight's duration. The incision gave him complete relief from pain, and his temperature on the following morning was $99^{\circ}$. For three days there was considerable discharge of pus from the wound, and the evening temperature ranged between $101^{\circ}$ and $102^{\circ}$. Nevertheless, the local condition steadily improved, and there was no reason for thinking that a mistake had been made in not trephining the bone. On the 8th, however, he began to complain of pain over the inner side of the right foot and the lower end of the right fibula. Nothing was to be seen amiss until the next afternoon, when slight redness and tenderness were noted at both these places, and the evening temperature rose to $103 \cdot 2^{\circ}$. The signs of inflammation had enormously increased by the 10th, and free incisions let out a large quantity of pus from beneath the periosteum, both of the fibula and of the first metatarsal bone, which were bare over a considerable area. Again there was relief from pain and fall of tempera. ture, and all three wounds were doing well, having been thoroughly irrigated with perchloride solution and dressed with sal alembroth dressings. The very next day, however, saw another attack of subperiosteal inflammation and suppuration; this time in the middle of the shaft of the left tibia, which was found bare for three inches after an incision had let out at least an ounce of pus. This focus of inflammation had no discoverable connexion with the original one at the upper end of the same bone, and was, I feel sure, quite distinct from it. The rapidity with which pus had been formed in all these places was most extraordinary. Detailed description is no longer necessary. There were no more abscesses, and the four wounds healed without further suppuration and without implication of bone. The boy began to put on flesh, and when he left on July $23 \mathrm{rd}$, with the wounds quite healed, his appearance was very different from that seen on his admission.

It would be wrong to call this a case of pyæmia, but the 
inflammation was clearly infective, and in the treatment regard was paid to the general as well as the local condition. The wounds were most choroughly purified, but, in addition to this, every effort was made to improve the boy's nutrition, and thereby to augment the resistant power of the tissues and fortify them against further activity of the opposing virus.

\section{DIFFERENTIATION IN RHEUMATIC DISEASES. ${ }^{1}$}

BY HUGH LANE, L.R.C.P. \&C.,

HONORARY MEDICAL OFFICER TO TIIE ROYAL UNITED HOSPITAL, DATH; HONORARY PHYSICIAN TO T'HE EASTERN

$$
\text { DISPENSARY, BATH. }
$$

IT may be regarded as a truism to say that, as the empire of medical science gradually widens its bounds, some of its departments which have in the past attracted but too scant a measure of serious notice are now beginning to receive the attention which is their due; and as in every department of human knowledge the synthetic method precedes the analytic, it is only when we pass from the stage of dealing in broad and general definitions and arrive at that of differentiating and classifying that we can truly say that a subject of this kind has begun to be properly grasped. And in the case of chronic rheumatic diseases so called, the time is not so very far distant when the employment of the single term "rheumatism" was held sufficient, not only as a definition, but as an explanation of numerous other diseases, which it is now found cannot be either diagnosed or cured by the device of merely comprising them under one common term and treating them all alike. It has, therefore, to be kept in view, in approaching the special study of rheumatism, that before grappling with it in its numerous and dis. tressing forms, these must be scientifically detailed and classified by the same methods by which all scientitic knowledge is reached-viz, inductive reasoning based upon extensive and minute observations.

Time was when to the old, the poor, and the overwrought, rheunitism seemed to be the natural and expected conclusion to a life of trouble only capable of being mitigated by the warm clothing which charity might supply, or by proximity to a friendly fireside. It was not provided for or guarded against until its presence made itself felt, for it was looked upon as kismet, a thing that could not be avoided; and the idea of preventing its approach, of looking for constitutional symptoms, or, in fact, attempting anything beyond the mere alleviation of its pain when once the victim was in its grip, was a thing unheard of. We see the burden that lies upon us to relieve these victims, to make life more tolerable for them and better worth living-in fine, to demonstrate to them that something is possible for them beyond mere physical existence, encumbered with pains and discomforts, and to teach them the truth and the meaning of that pregnant aphorism of antiquity, "Non est vivere sed valere vita." It will not, I trust, be looked upon as extravagance to say that by the increase of careful unremitting investigation into the various kinds of rheumatic diseases, especially with regard to their early and curable stages and the marks by which they may then be recognised, a better and higher result will inevitably be reached-viz., that in good time such symptoms and such effects will no longer be visible, and we shall no longer have amongst us the crippled frames we so frequently see and the lives of misery which are so often transmitted to an enfeebled posterity. This consummation, so devoutly to be wished, is, I fervently believe, no visionary's dream of the future, but is an actuality almost at hand. It is with such a result in view, and with the hope that the present proceedings may in some small degree contribute to it, that this paper has been written and the subject brought to the front. Its object is to endeavour to throw some further light upon the doubts which exist as to what the differences are between the varieties of rheumatio diseases so-called. By these I mean the diseases to which the terms "chronic rheumation," "rheumatoid arthritis," "rheumatic arthritis," and what is more popularly known as "rheumatic gout," are applied. A few months ago a work

Being the substance of a communication read before the Bristol Hedico-Cinrurgical Association on Nlay 14th, 1890. on this subject appeared by myself, in conjunction with my friend, Mr. Charles T. Griffiths, in which we set forth our opinions, based upon our experiences, and which were almost purely clinical observations. Although it cannot be hoped to better to any considerable extent those advanced in life who are auffering from a rheumatic affection, in spite of our utmost wishes and endeavours to do so, the subject which we think ought to hold a position of greater prominence than it does is that of giving attention to the early interference in the same disease or in one of those related to it, whether it be in a patient a little younger or much younger. For our experience has been that the tendency for the rheumatoidal element to develop in young persons is terribly on the increase. The result of these observations has been to convince us of the following: that the difference between rheumatism and rheumatoid arthritis is of a greater and far more extensive character than the text. books would lead to believe; and so markedly have clinical facts impressed this truth upon us that the occasion is gladly grasped to explain the results of our research. Fortunately for the success of our cause, our paths have led us into regions where rheumatism, rheumatoid arthritis, and rheumatic arthritis are grouped together for special treatment. In the Royal Mineral Water Hospital at Bath can be seen any day these diseases in all their phases, and with all their distinguishing differences, at any age and in every stage.

It must strike as being suggestive that we should have mentioned rheumatoid arthritis and rheumatic arthritis separately ; the reason for so doing will presently be made evident. But, first of all, let us look at rheumatism as com. pared with rheumatoid arthritis. This condition of chronic rheumatism is usually regarded as a most frequent one, but experience has shown that many of these cases of chronic rheumatism so-called, if inquired into more deeply, will prove to be one or other of the supposed allied diseases to be described later. When the sciatic nerve is attacked by rheumatism we call it "sciatica"; when the lumbar muscles, "lumbago"; when certain nerves, we employ the term "neuralgia"; and yet all, in spite of their change of name, claim a share in their relation to chronic rheumatism. We do not mean to offer any objection to this arrangement-it is, in fact, by adopting this quasi-complication we come to simplification; but when the term "chronic rheumatism" is used, it seems to me that it could not be utilised for better and clearer designation than in those cases in which the joints are painful but not swollen, or in which there is a neuralgia or even arthralgia associated with myalgia, or apart from it ; or in which the various fasciæ are affected, or in which there is a general neuralgic condition supervening on an acute attack of rheumatism. This is what we prefer to call "chronic rheumatism." But in speaking of the symptoms of rheumatoid arthritis, I will make reference to those symptoms which are sometinies put down as common to both. Let us imagine two patients sitting side by side, one with chronic rheumatism and the other with rheumatoid arthritis. Now, what do we see? In the rheumatoid arthritis case the first thing that strikes us is most probably the pallor of the patient, as compared with the chronic rheumatic. We look a little closer, and the next thing we perceive will most probably be the joints. The patient with chronic rheumatism will present in this feature little or nothing; whereas, on the other hand, the rheumatoid arthritis patient will be more or less crippled. There will be distinct muscular atrophy in the rheumatoid arthritis case, and the complexion will present the pallor mentioned before, showing on closer inspection yellowish tinges on the face, neck, and perhaps elsewhere. If we agk both patients if they ever had rheumatic fever, they both will probably say No; but further inquiry will elicit the probable fact that the family history of the patient with rheumatism will be a good one, or perhaps at the most a rheumatic one, while the rheumatoid arthritis patient in most cases gives or shows a strumous taint. It is upon the basis of this strumous taint that we feel we must look for further assistance to guide us in the treatment of this terribly crippling malady. It is nearly always present more or less. We are aware that this strumous history has not been particularly referred to in other descriptions of the disease. It being the almost invariable accompaniment has induced us to bring the matter forward. In fact, to look upon struma and rheumatoid arthritis as cause and effect has seemed to us the one plain characteristic in our investigations. Space does not allow of our going far afield for instances in support of the truth of this: the facts we 